\title{
Contribuição dos efeitos de genearcas e de famílias sobre a probabilidade de permanência em rebanhos da raça Nelore
}

\author{
[Breeders and family effects in stayability in Nellore herds] \\ C.R. Marcondes ${ }^{1}$, P.A. Vozzi $^{2}$, R.O. Araújo ${ }^{3}$, W.P. Glória ${ }^{3}$, R.B. Lôbo ${ }^{4}$ \\ ${ }^{1}$ Embrapa Amazônia Oriental \\ Tv. Dr. Enéas Pinheiro, s/n \\ 66095-100 - Belém, PA \\ ${ }^{2}$ Aluno de pós-graduação - FMRP-USP - Ribeirão Preto, SP \\ ${ }^{3}$ Aluno de graduação - UFT - Palmas, TO \\ ${ }^{4}$ Faculdade de Medicina de Ribeirão Preto - USP - Ribeirão Preto, SP
}

\begin{abstract}
RESUMO
Foram preditas diferenças esperadas na progênie para probabilidade de permanência no rebanho (stayability) de 4180 touros com filhas na base de dados do Programa de Melhoramento Genético da Raça Nelore, utilizando-se modelo de limiar unicaráter de touro-avô materno, sob metodologia bayesiana. Os touros foram classificados em ordem decrescente e aqueles com diferenças esperadas na progênie acima de $57,6 \%$, considerados como TOP $1 \%$, foram analisados quanto à genealogia visando avaliar a existência de efeito de família, bem como a contribuição dos genearcas e ancestrais da raça Nelore para a característica considerada. Os principais fundadores, que juntos somaram $18,8 \%$ dos genes presentes nos touros TOP $1 \%$, foram Karvadi IMP (com $8,2 \%$ dos genes, essencialmente via seu filho Chummak), Godhavari IMP (com 6\% de contribuição, via Kurupathy e Neófito), Rastã IMP e Falo da BV (2,5 e $2,1 \%$, respectivamente, via materna, pois não apresentaram parentesco com touros ancestrais). $\mathrm{O}$ touro Rolex, da variedade mocha, esteve presente em 12 linhas (maternas ou paternas), via seu neto Cardeal. Dos sete ancestrais da raça Nelore com maiores contribuições genéticas (que somaram 15,3\% dos genes), cinco foram da variedade mocha. Somente 28 animais aportaram $50 \%$ da variabilidade genética, evidenciando o baixo número de animais utilizados como reprodutores na raça Nelore.
\end{abstract}

Palavras-chave: bovino, Nelore, análise de pedigree, linhagens, permanência no rebanho

\begin{abstract}
Expected progeny differences (EPD) for stayability were estimated for 4,180 sires with daughters in the Program for Genetic Improvement of the Nellore Breed. The univariate threshold sire-maternal grandsire model was used, following a Bayesian methodology. The sires were ranked for stayability in descending order, and those whose EPD were higher than $57.6 \%$ were regarded as TOP1\%. Pedigree analysis was then conducted in order to establish whether a family tendency was present, as well as the contribution of Nellore founders and ancestors for the trait under consideration. The main founders, which together were responsible for $18.8 \%$ of the genes in TOP1\% sires, were Karvadi IMP (with $8.2 \%$ of genes, basically through its son Chummak), Godhavari IMP (with 6\% of genes, through Kurupathy and Neofito), Rastã IMP and Falo da BV (respectively with 2.5\% and 2.1\%, through mothers, since they are not related to the ancestor sires). Rolex, a polled sire, stayed in twelve lineages - paternal or maternal - through its grandson Cardeal. Among the seven Nellore ancestors with the highest genetic contributions (15.3\% of genes when put together), five were of the polled variety. Only 28 animals apportioned $50 \%$ of the total genetic variability, which is indicative of the small number of animals used as Nellore reproducers.
\end{abstract}

Keywords: beef cattle, Nellore, pedigree analysis, lineages, stayability

Recebido em 24 de fevereiro de 2006

Aceito em 12 de fevereiro de 2007

E-mail: cimarcon@yahoo.com 


\section{INTRODUÇÃO}

O acasalamento em linha é muito utilizado para a formação de linhagens diferentes dentro das raças, produzindo a separação da população em diferentes famílias, possibilitando a seleção das melhores e a eliminação das piores. Esse método de acasalamento foi o mais utilizado na formação de diferentes linhagens na raça Nelore (Magnabosco et al., 1997), sendo considerado uma ferramenta importante na conservação de determinados genótipos importados.

A idéia de parentesco pressupõe, em melhoramento animal, semelhança de genótipos. Diz-se que há parentesco entre dois indivíduos quando é maior a probabilidade de que eles tenham mais genes em comum do que dois outros quaisquer indivíduos da população. $\mathrm{O}$ termo linhagem refere-se a um grupo de animais que apresentam parentesco entre si, devido a um ancestral representado por um genearca, reprodutor fundador da fase contemporânea (material genético importado na década de 1960) da raça Nelore (Magnabosco et al., 1997).

Em uma dada linhagem, a existência de animais com mesma genealogia não implica, necessariamente, na mesma bagagem genética, pois a amostragem mendeliana ocorre durante a formação dos gametas. O uso intensivo de um determinado reprodutor possibilita a maior amplitude de variação no desempenho das progênies. Apesar do reduzido número de genearcas responsáveis pela formação do Nelore brasileiro, há evidências de diferentes perfis genéticos entre as linhagens, de acordo com o critério de seleção empregado (Lôbo et al., 2003b). Assim, na raça Nelore variedade mocha, apesar do pequeno tamanho efetivo da população (68 animais, segundo Faria et al., 2002) a existência de diferentes linhagens permitiria a exploração da complementariedade das características de interesse econômico.

A importância da identificação de diferenças no perfil genético de cada linhagem consiste na possibilidade de direcionar os acasalamentos, otimizando-os e, conseqüentemente, alcançando maiores progressos genéticos nas características incluídas no objetivo de seleção e evitando altos níveis de endogamia no rebanho ou na raça. Outros ganhos provenientes dos acasalamentos otimizados são o aumento (ou pelo menos a manutenção) da variabilidade genética aditiva e a sustentabilidade da raça, evitando-se a necessidade, ao médio e longo prazos, da incorporação extra de genes com uso de outras raças ou a importação de reprodutores sem qualquer tipo de avaliação genética (Lôbo et al., 2003b).

O objetivo deste trabalho foi identificar famílias e determinar a contribuição dos genearcas da raça Nelore, quanto ao desempenho para permanência da vaca no rebanho, a partir dos valores genéticos dos touros.

\section{MATERIAL E MÉTODOS}

As diferenças esperadas na progênie (DEP) dos 4180 touros, obtidas a partir das soluções resultantes da análise pelo multiple-trait Gibbs Sampler for animal models (MTGSAM) para características de limiar (Van Tassel et al., 1998), foram classificadas em ordem decrescente e estudadas as genealogias dos 42 melhores touros (também chamados de TOP $1 \%$ ou que apresentassem DEP acima de 57,6\%; Tab. 1). Maiores detalhes sobre a obtenção das DEPs encontram-se em Marcondes et al. (2005).

Tabela 1. Distribuição da diferença esperada na progênie para permanência no rebanho (Dstay), em percentis, na raça Nelore

\begin{tabular}{lc}
\hline TOP $(\%)$ & Dstay \\
\hline 0,1 & 62,0 \\
0,5 & 59,0 \\
1 & 57,6 \\
2 & 56,4 \\
3 & 55,6 \\
4 & 55,0 \\
5 & 54,4 \\
10 & 53,0 \\
15 & 52,0 \\
20 & 51,4 \\
25 & 51,0 \\
30 & 50,6 \\
40 & 50,1 \\
50 & 50,0 \\
100 & 37,4 \\
\hline
\end{tabular}

Fonte: Lôbo et al. (2003a).

TOP $1 \%=$ touro com diferença esperada na progênie acima de $57,6 \%$.

A Tab. 1 apresenta os percentis da característica permanência no rebanho, referindo-se às análises do ano de 2003. 
Utilizou-se o pacote PEDIG $^{\circledR}$ composto por uma série de programas escritos em linguagem Fortran 77 (Boichard, 2001). A contribuição genética dos touros fundadores e ancestrais pode ser medida pela proporção de genes ou alelos na população estudada, pelo número efetivo de fundadores, que representa o número de animais com igual contribuição que produziriam mesma variabilidade genética que aquela encontrada na população estudada (Vercesi et al., 2002), pelo número efetivo de ancestrais, que representa o número mínimo de animais, fundadores ou não, necessários para se explicar a diversidade genética total da população estudada (Vercesi et al., 2002) e pelo número de genomas remanescentes, que representa o número de fundadores com igual contribuição, sem haver perda de alelos por deriva na progênie e que produziriam a mesma diversidade genética encontrada na população estudada (Vercesi et al., 2002). O software disponibiliza, ainda, os parentescos entre os ancestrais considerados importantes para a característica auxiliando, assim, a identificação de uma ou mais famílias importantes para probabilidade de permanência no rebanho.

\section{RESULTADOS E DISCUSSÃO}

A proporção de genes dos fundadores da raça Nelore nos touros considerados TOP $1 \%$ para permanência no rebanho encontra-se representada na Fig. 1.
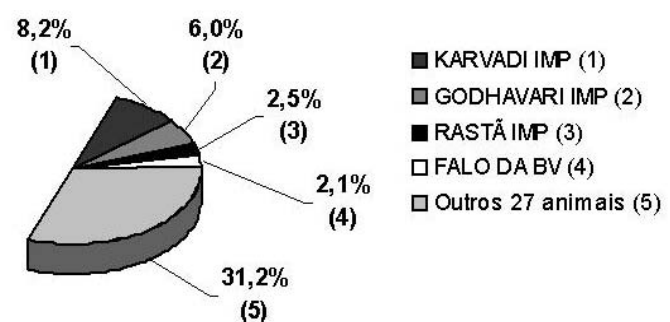

Figura 1. Proporção de genes dos importantes fundadores da raça Nelore incluídos no percentil dos melhores touros para permanência no rebanho.

Dos 34 touros com genealogia conhecida, 12 (35\%) possuem na linha materna ou paterna contribuição genética do fundador Godhavari IMP, essencialmente via Kurupathy e Neofito. Interessante seria relacionar a forte presença do touro Godhavari nos melhores para permanência no rebanho e os resultados do trabalho de Lôbo et al. (2003b), no qual foi detectado que a linhagem Godhavari apresentou a maior DEP média para reprodução de fêmeas (DPAC, ou DEP para produtividade acumulada, de $1,40 \mathrm{~kg}$ de bezerros desmamados ao ano) na sua geração de netos e, também, as maiores diferenças foram observadas entre a linhagem Godhavari e as linhagens Karvadi IMP e Rastã IMP $(3,46 \mathrm{~kg}$ de bezerros desmamados/ano, na geração de filhos e 2,54kg de bezerros desmamados/ano, na geração de netos, respectivamente). A linhagem Godhavari, portanto, apresentou filhos e netos que tiveram filhas mais produtivas, com maior número de bezerros e desmamados com melhores pesos que os descendentes dos touros Karvadi e Rastã. Como as filhas dos descendentes do touro Godhavari possuíam melhor habilidade materna e fertilidade, provavelmente há o reflexo disso na expressão da permanência no rebanho.

Na mesma proporção, observaram-se 12 linhas (maternas ou paternas) que terminavam no touro Rolex, via seu neto Cardeal (H 4013; Tab. 2). O genearca possui DPAC igual a $1,30 \mathrm{~kg}$ de bezerros desmamados/ano e o pai de Cardeal (Helix da SC) DPAC igual a 1,33kg de bezerros desmamados/ano (entre os 15\% melhores animais avaliados pelo Programa de Melhoramento Genético da Raça Nelore da Universidade de São Paulo - PMGRN-USP) e para habilidade materna (MP120) igual a $1,50 \mathrm{~kg}$ (entre os 20\% melhores).

Outro destaque fica por conta do touro Karvadi como genearca comum em 10 linhas maternas (essencialmente via Chummak) e somente uma linha paterna, ou seja, a importante contribuição do touro Karvadi é como tataravô, bisavô ou avô das mães dos touros com melhores DEPs para permanência no rebanho. Este fundador conferiu genes aos touros ancestrais Ídolo, Garoto e Fulminoso, todos mochos e TOP para DPAC e MP120 (Tab. 2).

Os outros touros fundadores, Rastã IMP (MP120 igual a 1,94kg) e Falo da BV (DPAC igual a $2,37 \mathrm{~kg}$ ) apresentaram significativa proporção de genes nos touros TOP para a característica, porém sem parentesco com aqueles considerados ancestrais importantes (Tab. 3; Fig. 2). Possivelmente, a disseminação de seus genes ocorreu pela via materna. 
Tabela 2. Proporção de genes dos ancestrais (exceto fundadores) dentro de alguns percentis elevados para permanência da vaca no rebanho e DEPs para produtividade acumulada e habilidade materna (MP120)

\begin{tabular}{lccccccc}
\multirow{2}{*}{ RGD } & \multirow{2}{*}{ Nome } & \multirow{2}{*}{ Data de nascimento } & \multicolumn{3}{c}{ Percentis } & DPAC & \multirow{2}{*}{ MP120 $(\mathrm{kg})$} \\
\hline 3425 & Amedabad & $29 / 08 / 1966$ & 3,0 & $5 \%$ & $10 \%$ & $(\mathrm{~kg})$ & \\
7447 & Chummak & $09 / 12 / 1965$ & 3,0 & 3,5 & 0,4 & $-2,36$ & 1,09 \\
H 0501 & Garoto & $15 / 07 / 1967$ & 2,8 & 1,2 & 0,3 & $-0,59$ & $-0,82$ \\
H 3815 & Ídolo & $01 / 01 / 1971$ & 2,0 & 0,8 & 0,5 & 2,53 & 2,03 \\
H 0729 & Fulminoso & $01 / 09 / 1968$ & 1,9 & 0,9 & 0,6 & 1,27 & 3,37 \\
H 4013 & Cardeal & $18 / 07 / 1976$ & 1,6 & 0,8 & 0,4 & 0,03 & 0,58 \\
H 4012 & Ping Pong & $31 / 01 / 1977$ & 1,0 & 0,3 & 0,2 & 1,53 & 0,55 \\
\hline
\end{tabular}

$\mathrm{DEP}=$ diferença esperada na progênie; $\mathrm{DPAC}=\mathrm{DEP}$ pra produtividade acumulada.

Tabela 3. Coeficiente de parentesco genético aditivo (\%) entre touros ancestrais com importante contribuição nos melhores touros para permanência no rebanho

\begin{tabular}{lccccccccccc}
\hline & FAL & CAR & KAR & AME & IDO & GOD & GAR & RAS & CHU & PIN & FUL \\
\hline FAL & 100 & & & & & & & & & & \\
CAR & 0 & 100 & & & & & & & & & \\
KAR & 0 & 0 & 100 & & & & & & & & \\
AME & 0 & 0 & 0 & 100 & & & & & & & \\
ÍDO & 0 & 0 & 0,8 & 3,2 & 100 & & & & & & \\
GOD & 0 & 0 & 0 & 25 & 12,6 & 100 & & & & & \\
GAR & 0 & 0 & 1,6 & 6,2 & 50 & 25 & 100 & & & & \\
RAS & 0 & 0 & 0 & 0 & 0 & 0 & 0 & 100 & & \\
CHU & 0 & 0 & 50 & 0 & 0,4 & 0 & 0,8 & 0 & 100 & & \\
PIN & 0 & 6,2 & 0 & 0 & 0 & 0 & 0 & 0 & 0 & 100 & \\
FUL & 0 & 0 & 1,6 & 6,2 & 12,6 & 25 & 25 & 0 & 0,8 & 0 & 100 \\
\hline
\end{tabular}

$\mathrm{FAL}=$ Falo da Bv; $\mathrm{CAR}=$ Cardeal; KAR $=$ Karvadi; $\mathrm{AME}=$ Amedabad; $\mathrm{IDO}=$ Ídolo; $\mathrm{GOD}=$ Godhavari; $\mathrm{GAR}=$ Garoto; RAS $=$ Rastã; $\mathrm{CHU}=$ Chummak; PIN= Ping Pong; FUL = Fulminoso.

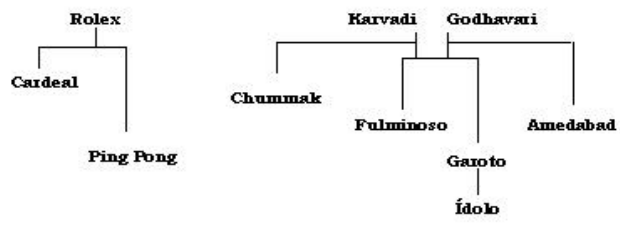

Figura 2. Relações de parentesco entre os ancestrais importantes para permanência no rebanho na raça Nelore.

Comparando-se as contribuições genéticas das famílias dos touros Karvadi e Godhavari com os resultados obtidos por Vozzi (2004), observa-se maior expressão da família Godhavari, quanto à permanência no rebanho, que na população geral de matrizes ativas do PMGRN-USP $(10,8 \%$ vs
3,6\%), assim como do ancestral Amedabad $(3,0 \%$ vs $1,3 \%)$. Em relação à família do genearca Kavardi, além da maior presença do touro Chummak nas linhas dos touros TOP $1 \%$ para permanência no rebanho (ele não possui contribuição significativa no rebanho de fêmeas ativas do PMGRN), a contribuição genética da família foi inferior àquela obtida para as matrizes $(11,2 \%$ vs $14,7 \%)$.

A maioria dos ancestrais importantes, como pode ser observado, é Nelore mocho. Uma suposição versaria sobre a existência de Red Polled na fixação do caráter mocho (Lima, comunicação pessoal 2003). Esta suposição torna-se coerente com os resultados obtidos por Meirelles et al. (1999) e por Günski (2001), sobre a existência de DNA mitocondrial de Bos taurus taurus na raça Nelore. A presença de DNA mitocondrial taurino também implicaria na existência de um pool gênico originado de animais indianos e europeus. Resultados de Ripamonte (2002) mostraram 6\% 
de genoma taurus em animais registrados (POI e PO) da raça Nelore.

O cálculo do número efetivo de fundadores, de ancestrais, e de genomas remanescentes, e o número de ancestrais responsáveis por $50 \%$ da variabilidade genética da permanência no rebanho, nos touros classificados como TOP1, TOP5 e TOP10\%, são apresentados na Tab. 4.

Tabela 4. Número efetivo de fundadores, ancestrais e genomas remanescentes nos melhores touros para permanência no rebanho (42 no TOP1\%; 209 no TOP5\% e 418 nos TOP $10 \%$ )

\begin{tabular}{lcccc}
\hline Número efetivo & & TOP $1 \%$ & TOP5\% & TOP $10 \%$ \\
\hline Fundadores & & 56 & 73 & 70 \\
Ancestrais & Entre & 48 e 54 & 64 e 73 & 62 e 70 \\
Genomas remanescentes & Machos & 21 & 30 & 30 \\
Número de ancestrais* & Fêmeas & 27 & 45 & 44 \\
\hline
\end{tabular}

* Responsáveis por 50\% da variabilidade genética.

A razão entre número efetivo de fundadores e de ancestrais, aproximadamente igual a 1, representa o efeito "gargalo" resultante da diminuição do número de reprodutores, ou seja, o número de fundadores é praticamente igual ao número de ancestrais, o que mostra grande redução no número de reprodutores utilizados. Boichard et al. (1997) relataram valor igual a 3 para a raça Normanda na França. Em 2002, Vercesi et al. (2002) e Faria et al. obtiveram valores de 1,44 e de 1,5, respectivamente, para as populações de Tabapuã e Nelore mocho brasileiras.

Maiores inferências não podem ser feitas, visto que não se trata de estudo populacional como o de Vercesi et al. (2002) e o de Faria et al. (2002), mas sim a busca de tendências familiares e avaliação da variabilidade genética no grupo de melhores touros para a característica considerada.

\section{CONCLUSÕES}

O estudo mostra que além das linhagens Karvadi, Godhavari e Rastã, as famílias dos touros Rolex e Falo da BV tiveram importante influência sobre a probabilidade de permanência no rebanho. Os baixos valores obtidos no número efetivo de fundadores, de ancestrais e na razão dos dois valores na raça Nelore indicam o uso de poucos reprodutores.

\section{AGRADECIMENTOS}

Os autores agradecem o apoio financeiro do PRONEX, FAPESP, CAPES, CNPq,
SEPLAN/TO, FINEP, ANCP, criadores do PMGRN e membros do Grupo de Genética Animal da UFT.

\section{REFERÊNCIAS BIBLIOGRÁFICAS}

BOICHARD, D. Pedig: a Fortran package for pedigree analysis suited for large populations. 2001. Disponível em $<$ http://dga.jouy.inra.fr/sgga/article.php3?id_artic le $=94>$. Acessado em: 17/07/2007.

BOICHARD, D.; MAIGNEL, L.; VERRIER, E. The value of using probabilities of gene origin to measure genetic variability in a population. $J$. Anim. Sci., v.29, p.5-23, 1997.

FARIA, F.J.C; VERCESI FILHO, A.E.; MADALENA, F.E. et al. Estrutura populacional da raça Nelore mocho. Arq. Bras. Med. Vet. Zootec., v.54, p.501-509, 2002.

GÜNSKI, R. J. Efeito do DNA mitocondrial sobre características de crescimento na raça Nelore. 2001. 69f. Tese (Doutorado) - Faculdade de Medicina de Ribeirão Preto, Universidade de São Paulo, Ribeirão Preto, SP.

LÔBO, R.B.; OLIVEIRA, H.N.; MAGNABOSCO, C.U. et al. Avaliação genética de animais jovens, touros e matrizes. Ribeirão Preto: Riber Gráfica e Editora, 2003a. 94p.

LÔBO, R.B.; MARCONDES, C.R.; TIVERON, G.C. et al. Perfil genético dos principais touros fundadores da raça Nelore na base de dados do PMGRN-USP. In: REUNIÃO ANUAL DA SOCIEDADE BRASILEIRA DE ZOOTECNIA, 
40., 2003, Santa Maria. Anais... Santa Maria: SBZ, 2003 b.

MAGNABOSCO, C.U.; CORDEIRO, C.M.T.; TROVO, J.B.F. et al. Catálogo de linhagens do germoplasma zebuíno: raça Nelore. Brasília: Embrapa-Cenargen, 1997. 52p. (Documento 23).

MARCONDES, C.R.; PANETO, J.C.C.; SILVA, J.A. II V. et al. Comparação entre análises para permanência no rebanho de vacas Nelore utilizando modelo linear e modelo de limiar. Arq. Bras. Med. Vet. Zootec., v.57, p.234-240, 2005.

MEIRELLES, F.V.; ROSA, A.J.M.; LÔBO, R.B. et al. Is the american zebu really Bos indicus? Genet. Mol. Biol., v.22, p.543-546, 1999.

RIPAMONTE, P. Estimativa da participação do genoma de Bos taurus no rebanho Nelore. 2002. 57f. Dissertação (Mestrado) - Faculdade de
Zootecnia e Engenharia de Alimentos, Universidade de São Paulo, Pirassununga, SP.

VAN TASSELL, C.P.; VAN VLECK, L.D.; GREGORY, K.E. Bayesian analysis of twinning and ovulation rates using a Multiple-Trait Threshold Model and Gibbs Sampling. J. Anim. Sci., v.76, p.2048-2061, 1998.

VERCESI, A.E.; FARIA, F.J.C.; MADALENA, F.E. et al. Estrutura populacional do rebanho Tabapuã registrado no Brasil. Arq. Bras. Med. Vet. Zootec., v.54, p.609-617, 2002.

VOZZI, P.A. Análise da estrutura $e$ variabilidade genética dos rebanhos participantes do Programa de Melhoramento Genético da Raça Nelore. 2004. 62f. Dissertação (Mestrado) - Faculdade de Medicina de Ribeirão Preto, Universidade de São Paulo, Ribeirão Preto, SP. 